\title{
Perceived control as a predictor of cardiovascular disease mortality in Poland. The HAPIEE study
}

\author{
Magdalena Kozela ${ }^{1}$, Agnieszka Doryńska ${ }^{1}$, Urszula Stepaniak ${ }^{1}$, \\ Krystyna Szafraniec ${ }^{1}$, Roman Topór-Mądry ${ }^{1}$, Witosława Misiowiec ${ }^{1}$, \\ Martin Bobak ${ }^{2}$, Andrzej Pająk ${ }^{1}$ \\ ${ }^{1}$ Department of Epidemiology and Population Studies, Institute of Public Health, \\ Faculty of Health Sciences, Jagiellonian University Medical College, Krakow, Poland \\ ${ }^{2}$ Department of Epidemiology and Public Health, University College London, United Kingdom
}

\begin{abstract}
Background: Neither the development in methods of treatment of coronary heart disease nor the changes in exposure to main cardiovascular disease (CVD) risk factors do not fully explain the trends in CVD mortality in Poland. An influence of psychosocial factors is considered. The aims of the study were: (1) to assess the relationship between perceived control and the prevalence of classic CVD risk factors; (2) to assess the relationship between perceived control and the risk of death from all causes and from CVD.

Methods: A cohort study with 5-year follow-up was conducted. Random sample of 10,728 permanent residents of Krakow aged 45-69 was examined. Perceived control was measured using a standard 11-item scale. The studied group was divided into four subgroups of people with very high, high, moderate, and low perceived control according to quartile values. Data on deaths and causes were obtained from the local register, death certificates and participants' families. An independent effect of perceived control on CVD mortality was assessed using Cox proportional hazards models.
\end{abstract}

Results: Low perceived control was strongly associated with a higher CVD mortality, independently of age, education, marital status, history of CVD, hypertension, hypercholesterolemia, smoking, body mass index, physical activity or diabetes in both men and women (HR 2.68, 95\% CI 1.36-5.31 and HR 5.18, 95\% CI 1.17-22.96, respectively). After adjustment for age, both in men and women, the highest risk of death from all causes was observed in persons with low perceived control. Further adjustment for covariates attenuated the relationship.

Conclusions: Perceived control is a strong independent predictor of CVD mortality and may be considered a CVD risk factor in the Polish urban population. (Cardiol J 2015; 22, 4: 404-412)

Key words: perceived control, cardiovascular disease, mortality, cohort study, psychosocial factors

\section{Introduction}

Cardiovascular disease (CVD) mortality started to decrease in Poland over 20 years ago but the diseases of circulatory system still remain the main cause of deaths [1]. Causes of the changes in the CVD mortality are not fully explained [2]. Introduction of reperfusion treatment, preventive

Address for correspondence: Magdalena Kozela, PhD, Department of Epidemiology and Population Studies,

Institute of Public Health, Faculty of Health Sciences, Jagiellonian University Medical College, ul. Grzegórzecka 20, 31-531 Kraków, Poland, tel: +48 12433 28 38, 602827 620, e-mail: m.frejek@uj.edu.pl; mkozela@cm-uj.krakow.pl 
pharmacotherapy and modification in the main risk factors such as hypertension, hypercholesterolemia or smoking contributed to the decreasing trend in CVD mortality. However, it seems unlikely that they were the triggering factors for the reversal of the trend at the beginning of the 1990s. Recent estimates made in the IMPACT Poland project showed that about $10 \%$ of the factors affecting the reduction in mortality due to ischemic heart disease remain unknown [3]. Also, the causes of the favorable spontaneous changes in the exposure to main CVD risk factors remain unclear. One of the hypotheses is that they were a result of macroeconomic changes and psychosocial factors. This is supported by the coincidence of CVD mortality decline during the political transition in Poland [4]. The mechanism of relationship between psychosocial factors and CVD is still the subject of research. The postulated mechanism indicate metabolic changes as a result of neuroendocrine response, imbalances of the sympathetic and parasympathetic nervous system, occurrence of metabolic syndrome or immunological response to inflammation [5-8]. The importance of psychosocial stress in development of CVD was established [8, 9].

One of the factors determining psychosocial stress is perceived control. This trait reflects person's perception, on whether the result of their behavior depends primarily on themselves, or rather it is attributed to fate, luck, coincidence or other external causes $[10,11]$. It has been found that low perceived control may be one of the factors explaining the differences in CVD morbidity by socio-economic status. In some studies, the differences in CVD prevalence by social class were explained by differences in perceived control, while differences in exposure to classic CVD risk factors contributed less [12-14]. The relationship between perceived control and CVD was found in studies from Western Europe and United States. In the INTERHEART cross-sectional study, the individuals with high perceived control were $25 \%$ less likely to have myocardial infarction compared to a group with low perceived control [15]. The WHITEHALL II cohort study showed that persons with low perceived control at work had $93 \%$ higher risk of cardiovascular events compared to those with high perceived control at work [16]. In women, over 2.5-fold higher risk of coronary heart disease was observed in persons with low perceived control at home, in comparison to women with high perceived control at home [17]. Also, later research performed in Norway and United Kingdom clearly indicated that low perceived control increased risk of death from all causes and death from CVD $[18,19]$. In the elderly population of Netherlands, it was found that low perceived control and low socio-economic status contributed to the risk of myocardial infarction in a greater extent than classic CVD risk factors [12].

In Central and East Europe, where for a long time socio-economic environment differed from Western Europe, no cohort studies to investigate the relationship between perceived control and CVD mortality have been carried-out. Numerous authors highlight the need for research to investigate causal relationships between psychosocial factors and CVD mortality in this region [20-23].

The aims of the study were: (1) To assess the relationship between perceived control and the prevalence of classic CVD risk factors; (2) To assess the relationship between perceived control and the risk of death from all causes and from CVD.

\section{Methods}

\section{Studied group}

The sample of 19,865 men and women was randomly selected from permanent residents of Krakow, who on December 31, 2002 were at age between 45 and 69 years. The drawing was conducted in the gender groups, 5-year age strata and in the 4 main districts of Krakow, assuming an equal representation of population in each stratum.

\section{Study design}

Total and cause specific mortality follow-ups were performed. The study was carried out within the Polish part of the HAPIEE project (Health, Alcohol and Psychosocial factors In Eastern Europe). The rationale of the study and methodology of the project were presented in detail previously [24, 25]. Brief information relevant for this publication is given below.

All participants gave written consent for participation in the study. The study was approved by the Bioethical Committee at the Jagiellonian University Collegium Medicum.

\section{Data collection}

At baseline trained nurses interviewed respondents in their homes using a standard questionnaire. Information on perceived control, age, education, marital status, employment, health status (history of CVD, number of chronic diseases, hypertension, diabetes, hypercholesterolemia), and health behaviors i.e. smoking and physical activity was obtained. 
Then all participants were invited to the clinic for anthropometric, blood pressure measurements and blood collection for biochemical tests.

Perceived control was assessed using a scale adapted from WHITEHALL II Study, the MacArthur Foundation Midlife Development Program and The New Barometer Studies [20, 23, 24, 26]. Respondents were asked to identify the extent to which they agree or disagree with presented statements in a 6 -point scale (from totally agree - code 0 to totally disagree - code 5 ). The final score was defined for respondents who answered at least 9 out of 11 questions. In persons who gave only 9 or 10 responses, missing values were replaced by the arithmetic mean of the others. The final result ranged from 0 (perceived lack of control) to 55 (the highest perceived control). The studied group was divided into 4 subgroups using sex-specific quartile values.

Height and weight were measured in the vertical position using electronic scales with a built-in ruler in participants wearing light indoor clothing and no shoes. Body mass index (BMI) was calculated in $\mathrm{kg} / \mathrm{m}^{2}$. Obesity was defined as BMI $\geq 30$ $\mathrm{kg} / \mathrm{m}^{2}$. Blood pressure was measured after at least 5 -min rest, in a sitting position, on the right arm using the automatic device Omron M5-I, 3 times in 2-min intervals. The average of the last 2 measurements was used in the analysis. Hypertension was defined as blood pressure $\geq 140 / 90 \mathrm{~mm} \mathrm{Hg}$ or receiving hypotensive treatment.

Blood was collected by venipuncture, from the respondents in the fasting state (after at least $12 \mathrm{~h}$ after the last meal), in the sitting position. Time of tourniquet use was limited to $<1 \mathrm{~min}$. Biochemical analyses were conducted on the same day, less than $4 \mathrm{~h}$ after the time of collection. Prior to centrifugation, samples were stored at $4^{\circ} \mathrm{C}$. Hypercholesterolemia was defined as total cholesterol $\geq 5 \mathrm{mmol} / \mathrm{L}$ or low density lipoprotein cholesterol $\geq 3 \mathrm{mmol} / \mathrm{L}$ or receiving lipid-lowering treatment. Diabetes was defined as having fasting plasma glucose $\geq 7 \mathrm{mmol} / \mathrm{L}$ or having diabetes diagnosed by the doctor.

Low physical activity was recognized if total duration of physical activity was shorter than $25 \mathrm{~h}$ in a typical week. Current smoking status was defined in persons smoking cigarettes regularly or occasionally and ex-smoking if they had smoked in the past but stopped. The remaining participants were classified as non-smokers. The number of chronic diseases was assessed according to the answer to the question, in which respondents selected from a given list of diseases those, which were diagnosed in them by a doctor (with or without hospitalization). History of CVD was coded as a dichotomous variable.

Follow-up was carried out until for all participants at least a 5-year observation was reached. Deaths from all causes were registered. Information on deaths was obtained from the Local Register of residents of the City of Krakow. Causes of deaths, according to the International Statistical Classification of Diseases and Related Health Problems - Review X (ICD-10), were obtained from families and Central Statistical Office. CVD deaths were defined as ICD codes I.00-I.99.

\section{Statistical analyses}

To assess the relationships between CVD risk factors and perceived control logistic regression models were used, except for smoking which had 3 categories and multinomial logit model was used. Results were presented as odds ratios $(\mathrm{OR})$ of the presence of risk factors by perceived control strata. Kaplan-Meier plots were used for a graphical presentation of survival by perceived control. Differences between survival curves were assessed using log-rank test. Cox proportional hazards models were used to assess the independent effect of perceived control on the risk of death from all causes and the risk of CVD death. Results were presented as hazard ratios (HR) with 95\% confidence intervals (CI). The reference group was very high perceived control. Analyses were performed using STATA v.11 statistical package (StataCorp LP, Texas, USA).

\section{Results}

There were 10,728 men and women examined in baseline examination (response rate $61 \%$ ). Out of them $185(1.7 \%)$ had not data on perceived control available and a total number of 10,543 individuals were included to a cross-sectional analysis. Further $688(7 \%)$ did not agree for follow-up, and finally 4,789 men and 5,066 women were considered to the prospective study.

Descriptive statistics for age, education, marital status, occupational status, history of CVD risk factors, number of chronic diseases and perceived control were presented in Table 1. Men were slightly older than women $(57.94 \pm 6.97$ vs. $57.41 \pm$ \pm 7.99 years; $p<0.001$ ), more frequently had university education, but compared to women, lower proportion had secondary education $(\mathrm{p}<0.001)$. In women, higher proportions of singles (not married or widowed) as well as economical inactive 
Table 1. Distribution of age, perceived control, education, marital status, occupational status, cardiovascular disease (CVD) risk factors, number of chronic diseases and cardiovascular disease by gender.

\begin{tabular}{lccc}
\hline & Men $(\mathbf{n}=\mathbf{5}, \mathbf{1 3 4})$ & Women $(\mathbf{n}=\mathbf{5}, \mathbf{4 0 9})$ & $\mathbf{P}$ \\
\hline Perceived control & $36.99 \pm 7.49$ & $36.28 \pm 7.56$ & $<0.001$ \\
Age & $57.94 \pm 6.97$ & $57.41 \pm 7.99$ & $<0.001$ \\
Education: & & & $<0.001$ \\
$\quad$ Vocational and lower & $1,893(36.9 \%)$ & $1,548(28.65 \%)$ & \\
High & $1,689(32.92 \%)$ & $2,392(44.26 \%)$ & \\
$\quad$ University & $1,548(30.28 \%)$ & $1,464(27.09 \%)$ & \\
Marital status: & & & $<0.001$ \\
$\quad$ In relationship & $4,437(86.64 \%)$ & $3,589(66.49 \%)$ & \\
Single & $684(13.36 \%)$ & $1,809(33.51 \%)$ & \\
Occupational status: & & & \\
$\quad$ Economically active & $2,494(48.65 \%)$ & $2,101(38.91 \%)$ & $<0.001$ \\
$\quad$ Economically inactive & $2,632(51.35 \%)$ & $3,299(61.09 \%)$ & \\
Hypertension & $3,194(68.10 \%)$ & $2,886(58.15 \%)$ & $<0.001$ \\
Hypercholesterolemia & $3,838(84.54 \%)$ & $4,211(87.78 \%)$ & $<0.001$ \\
Diabetes & $799(17.63 \%)$ & $622(13.07 \%)$ & $<0.001$ \\
Low physical activity & $3,747(77.47 \%)$ & $3,456(67.62 \%)$ & $<0.001$ \\
Obesity & $1,217(27.43 \%)$ & $1,607(34.24 \%)$ & $<0.001$ \\
Smoking status: & & & $<0.001$ \\
$\quad$ Non-smoker & $1,453(27.87 \%)$ & $2,785(50.57 \%)$ & \\
Ex-smoker & $1,884(36.14 \%)$ & $1,142(20.82 \%)$ & \\
$\quad$ Current smoker & $1,876(35.99 \%)$ & $1,557(28.39 \%)$ & \\
Number of chronic diseases: & & & \\
At most one & $2,386(56.86 \%)$ & $2,238(50.46 \%)$ & \\
Two & $910(21.69 \%)$ & $1,105(24.92 \%)$ & \\
$\quad$ Three or more & $900(21.45 \%)$ & $1,092(24.62 \%)$ & \\
History of CVD & $1,124(23.65 \%)$ & $1,053(20.93 \%)$ & \\
\hline
\end{tabular}

individuals were observed. The most frequent CVD risk factor was hypercholesterolemia, which occurred in $84.54 \%$ of men and $87.78 \%$ of women $(\mathrm{p}<0.001)$. The least frequent was diabetes, which was found in $17.63 \%$ of men and $13.07 \%$ of women ( $\mathrm{p}<0.001)$. Hypertension, diabetes, low physical activity and smoking were more frequent in men $(\mathrm{p}<0.001)$. Women were more often exposed to obesity $(\mathrm{p}<0.001)$. Distribution of perceived control was presented in Figure 1. Mean perceived control was higher in men compared to women $(36.99 \pm 7.49$ points vs. $36.28 \pm 7.56$ points; $\mathrm{p}<$ $<0.001$, respectively). The first quartile, median and third quartile were respectively: $\mathrm{Q} 1=32, \mathrm{Me}=38$, $\mathrm{Q} 3=42$ in men and $\mathrm{Q} 1=31, \mathrm{Me}=37, \mathrm{Q} 3=42$ in women. The relationship between perceived control and CVD risk factors was presented in Table 2. In men, participants with moderate and low perceived control had higher prevalence of low physical activity (by 36\% and twice higher, respectively), compared to subjects with very high perceived control. Moderate and low perceived control were also associated with higher prevalence of smoking by $32 \%$ and $47 \%$, respectively. Obesity was $24 \%$ less prevalent in men with low perceived control compared to very high perceived control. In women, compared to with very high perceived control, high, moderate and low perceived control was associated with higher prevalence of hypertension by up to $32 \%$ and with smoking by up to $61 \%$, respectively. Low perceived control was also related with $49 \%$ higher prevalence of low physical activity. In both sexes, perceived control was not associated with hypercholesterolemia or diabetes.

Kaplan-Meier survival curves by perceived control for all-cause and CVD mortality for men and women were presented in Figure 2. The probability of survival in subjects with low perceived control 


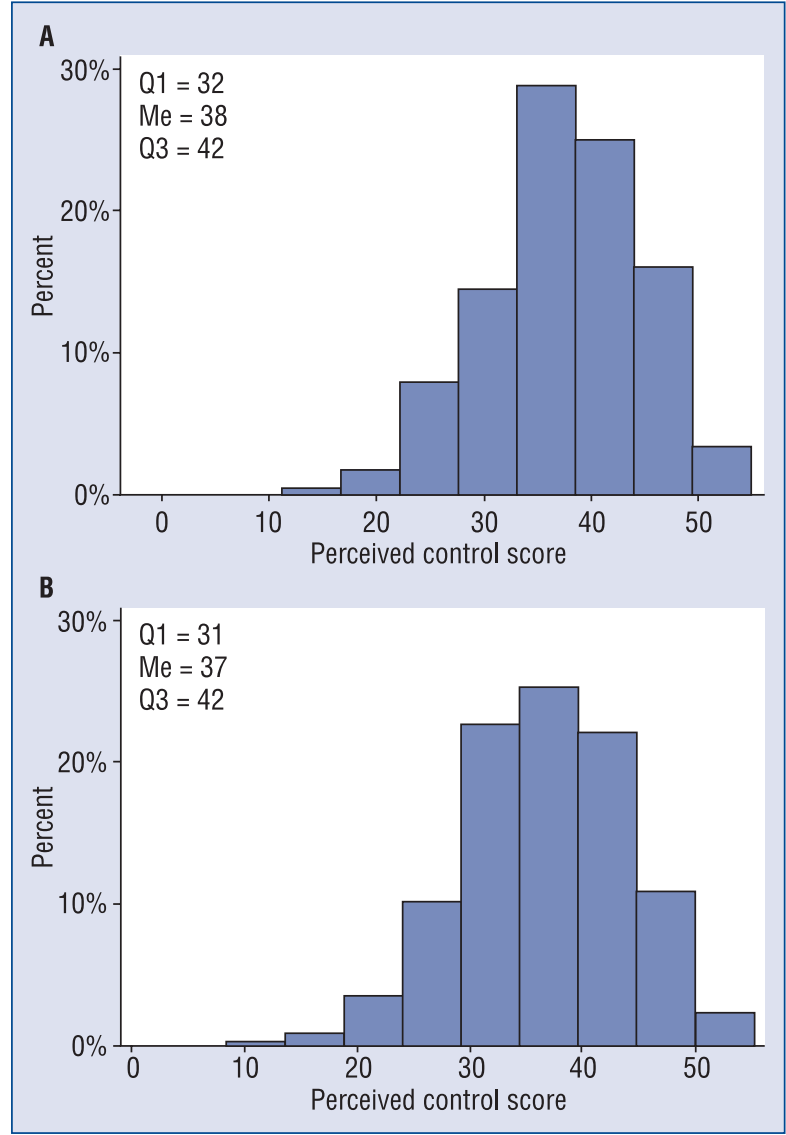

Figure 1. Distribution of perceived control; A. Men; B. Women

was lower than in the groups with higher levels of perceived control $(\mathrm{p}<001)$. Similarly, in CVD mortality, the lowest probability of survival had both men and women with low perceived control.

After adjustment for age, men with low perceived control had over a 4-fold higher risk of CVD death, and men with moderate perceived control had a 2.5-fold higher risk of CVD death than men with very high perceived control (Table 3 ). Further adjustment for education, marital status, history of CVD, hypertension, hypercholesterolemia, diabetes, smoking, physical activity and BMI attenuated the relationship, but still men with low perceived control had nearly a 3 -fold higher risk of CVD death compared to men with very high perceived control. In women, a significant association was found only in low perceived control. After adjustment for confounders in women with low perceived control, over a 5-fold higher risk of CVD death was found, compared to women with very high perceived control.

The relationship between perceived control and all-cause mortality was weaker than in the case

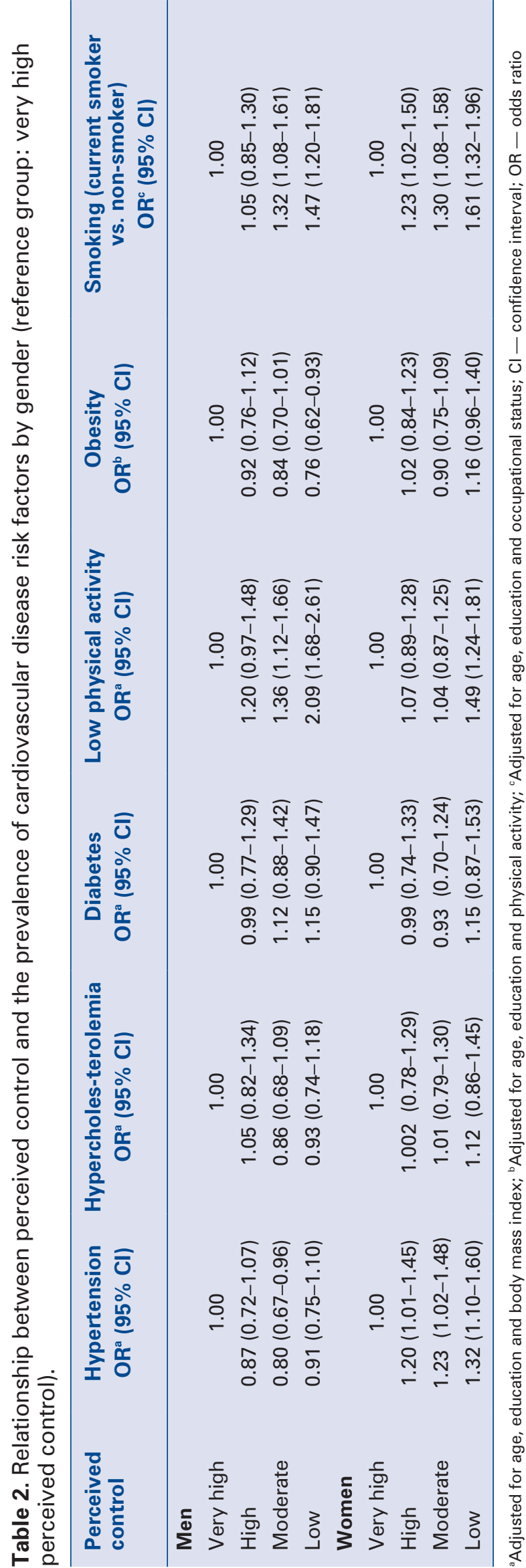




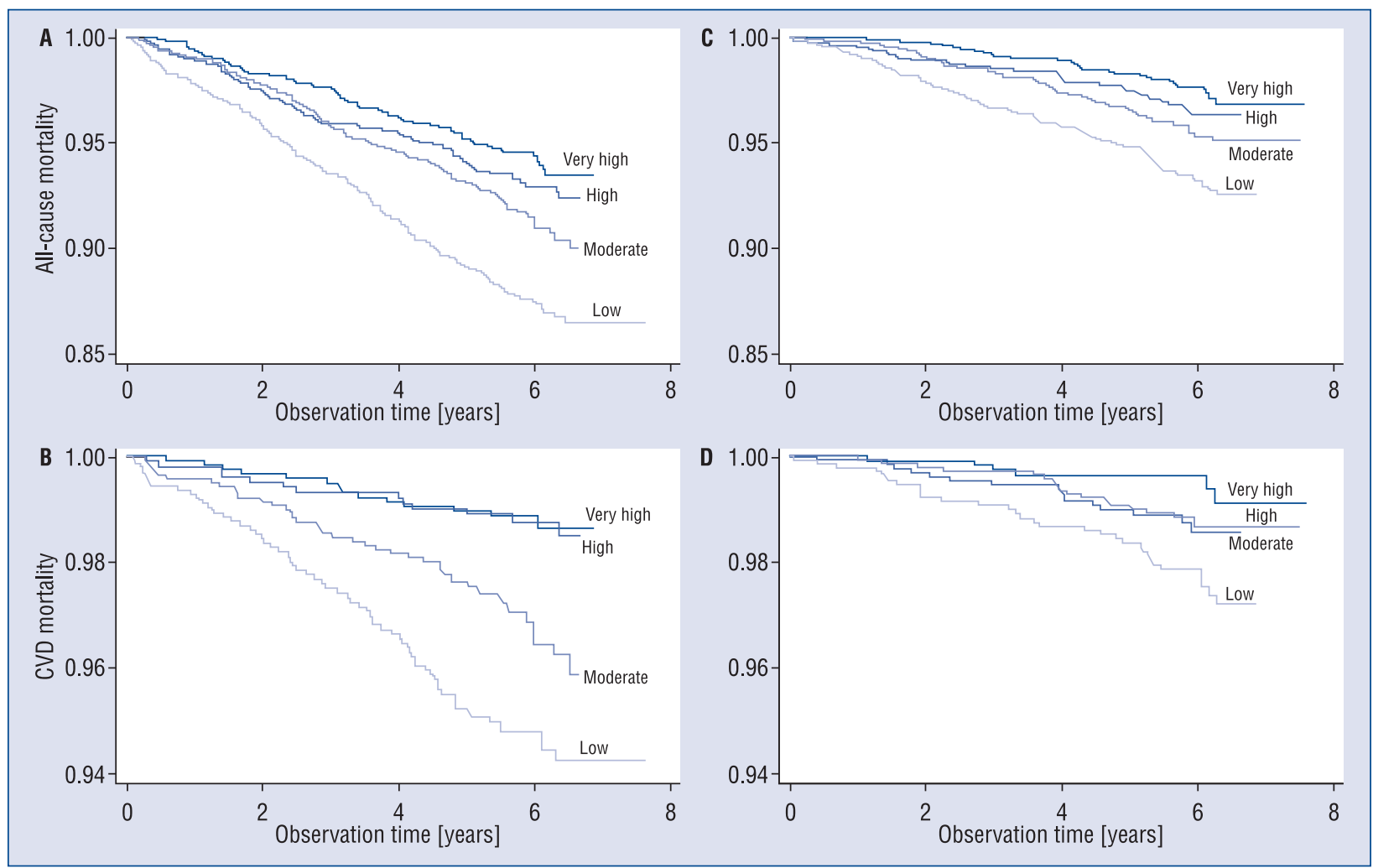

Figure 2. Kaplan-Meier survival curves by perceived control; A, B. Men; C, D. Woman; CVD — cardiovascular disease.

Table 3. Association between perceived control and cardiovascular disease mortality (reference group: very high perceived control).

\begin{tabular}{|c|c|c|c|c|}
\hline Perceived control & $\mathrm{HR}^{\mathrm{a}}(95 \% \mathrm{CI})$ & $\mathrm{HR}^{\mathrm{b}}(95 \% \mathrm{Cl})$ & $\mathrm{HR}^{\mathrm{c}}(95 \% \mathrm{CI})$ & $\operatorname{HR}^{d}(95 \% \mathrm{Cl})$ \\
\hline \multicolumn{5}{|l|}{ Men } \\
\hline Very high & 1.00 & 1.00 & 1.00 & 1.00 \\
\hline High & $1.01(0.47-2.15)$ & $0.98(0.46-2.08)$ & $0.92(0.43-1.97)$ & $0.73(0.29-1.83)$ \\
\hline Moderate & $2.46(1.35-4.50)$ & $2.34(1.28-4.28)$ & $2.03(1.10-3.75)$ & $1.80(0.89-3.65)$ \\
\hline Low & $4.14(2.32-7.39)$ & $3.82(2.13-6.85)$ & $3.16(1.75-5.69)$ & $2.68(1.36-5.31)$ \\
\hline \multicolumn{5}{|l|}{ Women } \\
\hline Very high & 1.00 & 1.00 & 1.00 & 1.00 \\
\hline High & $2.10(0.82-5.37)$ & $2.09(0.82-5.34)$ & $1.88(0.73-4.85)$ & $3.67(0.79-17.06)$ \\
\hline Moderate & $1.82(0.72-4.63)$ & $1.73(0.68-4.42)$ & $1.62(0.63-4.14)$ & $3.64(0.79-16.71)$ \\
\hline Low & $3.72(1.55-8.92)$ & $3.52(1.46-8.53)$ & $3.18(1.31-7.73)$ & $5.18(1.17-22.96)$ \\
\hline
\end{tabular}

${ }^{a}$ Adjusted for age; ${ }^{b}$ Adjusted for age, education, marital status; ${ }^{\circ}$ Adjusted for age, education, marital status, history of cardiovascular disease (myocardial infarction, stroke, ischemic heart disease); ${ }^{\mathrm{d}}$ Adjusted for age, education, marital status, history of cardiovascular disease (myocardial infarction, stroke, ischemic heart disease), hypertension, hypercholesterolemia, smoking, body mass index, physical activity, diabetes; $\mathrm{Cl}$ - confidence interval; $\mathrm{HR}$ - hazard ratio

of CVD mortality (Table 4). After adjustment for age, the risk of death from all causes was nearly $40 \%$ higher in men with moderate perceived control, and more than twice as high in men with low perceived control, compared to men with a very high perceived control. In women, after adjustment for age, persons with low perceived control had a 2.5 times higher risk of death compared to women with very high perceived control. In both sexes, further adjustment for education, marital status, chronic diseases, and CVD risk factors attenuated this relationship. 
Table 4. Association between perceived control and all-cause mortality (reference group: very high perceived control).

\begin{tabular}{lcccc}
\hline Perceived control & $\mathbf{H R}^{\mathbf{a}}(\mathbf{9 5} \% \mathbf{C l})$ & $\left.\mathbf{H R}^{\mathrm{b}} \mathbf{( 9 5 \%} \mathbf{C l}\right)$ & $\left.\mathbf{H R}^{\mathbf{c}} \mathbf{( 9 5 \%} \mathbf{C l}\right)$ & $\left.\mathbf{H R}^{\mathbf{d}} \mathbf{( 9 5 \%} \mathbf{C l}\right)$ \\
\hline Men & & & & \\
Very high & 1.00 & 1.00 & 1.00 & 1.00 \\
High & $1.15(0.83-1.61)$ & $1.11(0.80-1.55)$ & $1.08(0.75-1.54)$ & $1.07(0.73-1.57)$ \\
Moderate & $1.39(1.03-1.87)$ & $1.25(0.92-1.68)$ & $1.12(0.80-1.56)$ & $1.09(0.77-1.55)$ \\
Low & $2.10(1.58-2.79)$ & $1.78(1.33-2.37)$ & $1.49(1.08-2.05)$ & $1.31(0.93-1.86)$ \\
Women & 1.00 & & & \\
Very high & $1.28(0.79-2.07)$ & $1.22(0.75-1.99)$ & $1.19(0.70-2.02)$ & $1.01(0.59-1.75)$ \\
High & $1.56(0.99-2.45)$ & $1.46(0.92-2.30)$ & $1.40(0.85-2.30)$ & $1.12(0.67-1.88)$ \\
Moderate & $2.49(1.62-3.83)$ & $2.30(1.49-3.55)$ & $1.84(1.14-3.04)$ & $1.52(0.92-2.52)$ \\
Low & & &
\end{tabular}

${ }^{a}$ Adjusted for age; ${ }^{b}$ Adjusted for age, education, marital status; ${ }^{\circ}$ Adjusted for age, education, marital status, number of chronic diseases; ${ }^{d}$ Adjusted for age, education, marital status, number of chronic diseases, smoking, hypertension, hypercholesterolemia, body mass index and physical activity; $\mathrm{Cl}$ - confidence interval; $\mathrm{HR}$ - hazard ratio

\section{Discussion}

We found a strong inverse, independent association between perceived control and CVD mortality. However, after adjustment for CVD risk factors, the relationship between perceived control and all-cause mortality was not significant.

There are some limitations in the interpretation of the results presented. The Polish version of perceived control scale was published in 2002 [24] but its external consistency was not fully assessed, because there was no other Polish tool for the assessment of perceived control in the general population. However, this tool is widely used for the assessment of perceived control in large epidemiological studies [15-17, 20, 21, 23, 27] and its internal consistency was satisfying [28]. Although the study group was drawn from the general population, nearly $39 \%$ of individuals did not participate in the baseline examination. This could have a negative impact on the representativeness of the sample. Such a participation rate, however, is not considerably different from response rates obtained in studies in this age group [29,30]. Comparison of mortality among respondents and non-respondents of the Polish part of the HAPIEE project showed that respondents were the healthier part of the general population [31]. Thus, the relationship between perceived control and mortality in the population of Krakow might be even stronger than our results showed.

Despite the above limitations, up to our best knowledge this is the first attempt to assess the independent effect of perceived control on mortal- ity in the well-planned prospective cohort study including large, random sample of the general population. The results obtained are consistent with studies from Western Europe, in which low perceived control was associated with increased risk of CVD events and CVD mortality [15-17, 19]. Our study confirmed the independent effect of perceived control on CVD mortality in population of Eastern Europe. Also, our results confirmed the associations between perceived control and CVD risk factors [27, 32, 33]. However, not all CVD risk factors were related significantly with perceived control. In contrast to other studies, a positive association between perceived control and obesity was found in men, despite higher prevalence of low physical activity in men with low perceived control. It may suggest that the impact of perceived control on CVD mortality by the mediation effect of CVD risk factors is limited. This emphasizes the importance of perceived control as an independent determinant of risk of CVD death. Relation between perceived control, low physical activity and obesity could be explained partially at least by the poorer health status of participants with low perceived control. However, the adjustment for the presence of chronic diseases at baseline should contribute to control of the effect of health status in the relation between perceived control and mortality.

Despite involving more than 10,000 of participants, statistical power was too low to demonstrate a significant effect of perceived control on all-cause mortality. There is some evidence from several studies on inverse relationship between 
perceived control and mortality from all causes [34, 35]. The effect described by other authors was not supported by our results. After adjustment for age, education, marital status, chronic diseases, smoking, hypertension, hypercholesterolemia, physical activity, and BMI, there was no association between perceived control and all-cause mortality. This also might be due to differences in the standardization of the final models. A significant proportion of all deaths are due to CVD. Our results clearly indicate that the relationship between perceived control, and the risk of death from all causes was mostly explained by the influence of CVD risk factors, the impact of which was not always taken into account in the other studies. In addition, all cited studies refer only to research carried out in Western Europe and United States, where socio-economic conditions and mortality rates still remain different in comparison to the countries of Central and Eastern Europe.

The differences in the estimates may also be the result of heterogeneity of perceived control measurement [15, 17, 27]. Some authors postulate that lack of one standard tool for perceived control measurement is an important weakness of research in this field [10]. However, regardless of the heterogeneity of the measurement methods, perceived control seems to be an important characteristic which should not be ignored in research of determinants of mortality in modern societies.

The relationship between perceived control and CVD mortality is confirmed by the results from other fields of science. In psychology, perceived control was described as a trait which influences the perception the situation as more or less stressful [36]. It is therefore one of the characteristics which determine the physiological stress response as the hypothalamic-pituitaryadrenal axis is also affected psychologically [37]. High perceived control was found to be related with lower concentrations of cortisol and in individuals with high perceived control cortisol levels quicker returned to baseline levels after a stressful situation than in persons with low perceived control [38]. Chronic psychosocial stress may contribute to the acceleration of the atherosclerotic process. There is some evidence which allow assertion that the development of CVD can be affected by chronic unquenched stimulation as a result of the stress response to the psychosocial situation [9].

Our study supports the hypothesis that psychosocial characteristics might appear as independent determinants of CVD, and changes in exposure to psychosocial factors could partially explain the changes in CVD mortality trends.

\section{Conclusions}

Low perceived control is a strong independent predictor of CVD mortality and may be considered a CVD risk factor in Polish urban population.

The relationship between perceived control and all-cause mortality was explained by the influence of classic CVD risk factors.

\section{Acknowledgements}

The HAPIEE Study was funded by the Wellcome Trust, the MacArthur Foundation and National Institute on Aging. The authors are grateful to all investigators of The HAPIEE Project and to the participants of the surveys.

\section{Conflict of interest: None declared}

\section{References}

1. World Health Organisation, Health for All Database, April, 2014.

2. Pająk A, Kozela M. Cardiovascular Disease in Central and East Europe. Public Health Reviews, 2012; 33: 2.

3. Bandosz P, O'Flaherty M, Drygas W et al. Decline in mortality from coronary heart disease in Poland after socioeconomic transformation: Modelling study. BMJ, 2012; 344: d8136. doi: 10.1136/bmj.d8136.

4. Stuckler D, King L, McKee M. Mass privatization and the postcommunist mortality crisis. Lancet, 2009; 373: 399-407. doi: 10.1016/S0140-6736(09)60005-2.

5. Rozanski A, Blumenthal JA, Kaplan J. Impact of psychological factors on the pathogenesis of cardiovascular disease and implications for therapy. Circulation, 1999; 99: 2192-2217.

6. Sgoutas-Emch SA, Cacioppo JT, Uchino BN et al. The effects of an acute psychological stressor on cardiovascular, endocrine, and cellular immune response: A prospective study of individuals high and low heart rate reactivity. Psychophysiology, 1994; 31: 264-271.

7. Kośmicki M. Stres psychospołeczny jako czynnik ryzyka choroby wieńcowej. Przew Lek, 2002; 5: 28-37.

8. Smith TW, MacKenzie J. Personality and risk of physical illness. Ann Rev Clin Psychol, 2006; 2: 435-467.

9. Kopp MS, Réthelyi J. Where psychology meets physiology: Chronic stress and premature mortality: The Central-Eastern European health paradox. Brain Research Bulletin, 2004; 62: 351-367.

10. Kościelak R. Poczucie umiejscowienia kontroli i przekonania o własnej skuteczności w zdrowiu i chorobie. Oficyna Wydawnicza Impuls, Kraków 2010.

11. Skinner EA. A guide to constructs of control. J Personality Social Psychol, 1996; 71: 549-570.

12. Bosmaa H, Van Jaarsveldb CHM, Tuinstrab J, Sanderman R. Low control beliefs, classical coronary risk factors, and socioeconomic differences in heart disease in older persons. Social Science Med, 2005; 60: 737-745. doi: 10.1016/j.socscimed.2004.06.018.

13. Bailis DS, Segall A, Mahon MJ, Chipperfield JG, Dunn EM. Perceived control in relation to socioeconomic and behavioral resources for health. Social Science Med, 2001; 52: 1661-1676. 
14. Bosma H, Schrijvers C, Mackenbach JP. Socioeconomic inequalities in mortality and importance of perceived control cohort study. Br Med J, 1999; 319: 1469-1470.

15. Rosengren A, Hawken S, Ounpuu S et al. Association of psychosocial risk factors with risk of acute myocardial infarction in 11119 cases and 13648 controls from 52 countries (the INTERHEART study): Case-control study. Lancet, 2004; 364: 953-962. doi:10.1016/S0140-6736(04)17019-0.

16. Bosma H, Marmot MG, Hemingway H, Nicholson AC, Brunner E, Stansfeld SA. Low job control and risk of coronary heart disease in Whitehall II (prospective cohort) study. BMJ, 1997; 314: 558. doi: 10.1136/bmj.319.7223.1469.

17. Chandola T, Kuper H, Singh-Manoux A, Bartley M, Marmot M. The effect of control at home on CHD events in the Whitehall II study: Gender differences in psychosocial domestic pathways to social inequalities in CHD. Social Science Med, 2004; 58: 1. doi: 10.1016/S0277-9536(03)00352-6.

18. Dalgard OS., Håheim LL. Psychosocial risk factors and mortality: A prospective study with special focus on social support, social participation, and locus of control in Norway. J Epidemiol Community Health, 1998; 52: 476-481.

19. Surtees PG, Wainwright NW, Luben R, Wareham NJ, Bingham SA, Khaw KT. Mastery is associated with cardiovascular disease mortality in men and women at apparently low risk. Health Psychol, 2010; 29: 412-420 doi: 10.1037/a0019432.

20. Bobak M, Pikhart H, Rose R, Hertzman C, Marmot M. Socioeconomic factors, material inequalities, and perceived control in self-rated health: Cross-sectional data from seven post-communist countries. Social Science Med, 2000; 51: 1343-1350. doi: 10.1016/S0277-9536(00)00096-4.

21. Lundberg J, Bobak M, Malyutina S, Kristenson M, Pikhart H. Adverse health effects of low levels of perceived control in Swedish and Russian community samples. BMC Public Health, 2007; 2: 314. doi:10.1186/1471-2458-7-314.

22. Lachman ME. Perceived control over aging-related declines: Adaptive beliefs and behaviors. Current Directions Psychol Science, 2006; 15: 282.

23. Bobak M, Pikhart H, Hertzman C, Rose R, Marmot M. Socioeconomic factors, perceived control and self-reported health in Russia. A cross-sectional survey. Social Science Med, 1998; 47: 269-279. doi: 10.1016/S0277-9536(98)00095-1.

24. Pająk A. Psychospołeczne i żywieniowe czynniki ryzyka chorób układu krążenia. Założenia i cele projektu oraz metody badania przekrojowego. Przegl Lek, 2002; 59: 993-998.
25. Peasey A, Bobak M, Kubinova R et al. Determinants of cardiovascular disease and other non-communicable diseases in Central and Eastern Europe: Rationale and design of the HAPIEE study. BMC Public Health, 2006; 6: 255.

26. Lachman ME, Boone JJ. Multiple paths of midlife development. The University of Chicago Press, Chicago 1997.

27. Lee C, Ford J, Gramotnev H. The life control scale: validation with a population cohort of middle-aged Australian women. Int J Behavioral Med, 2009; 16: 148-157.

28. Nunnaly J. Psychometric Theory. McGraw-Hill, Nowy York 1978.

29. Center for Disease Control and Prevention, National Health and Nutrition Examination Survey. NHANES Response Rates and CPS Totals. http://www.cdc.gov/nchs/nhanes/response_rates_ cps.htm [1.06.2012].

30. Arcari A, Magnacca S, Bracone F et al. Relation between pulmonary function and 10-year risk for cardiovascular disease among healthy men and women in Italy: The Moli-sani Project. Eur J Prev Cardiol, 2013; 20: 862-871. doi: 10.1177/204748731244 7904.

31. Topór-Mądry R, Bobak M, Pajak A. 5-year mortality in respondents and non-respondent for the cohort study of 20000 randomly selected middle aged men and women. The HAPIEE Project. Eur J Preventive Cardiol, 2012; 19: 1 suppl.

32. Adolfsson B, Andersson I, Elofsson S, Rössner S, Undénc AL. Locus of control and weight reduction. Patient Education Counseling, 2005; 56: 55-61.

33. Peterson C, Stunkard AJ. Personal control and health promotion. Social Scientific Med, 1989; 28: 819-828.

34. Infurna FJ, Gerstorf D, Ram N, Schupp J, Wagner GG. Long-term antecedents and outcomes of perceived control. Psychology Aging, 2011; 26: 559-575. doi: 10.1037/a0022890.

35. Infurna FJ, Ram N, Gerstorf D. Level and change in perceived control predict 19-year mortality: Findings from the Americans' changing lives study. Dev Psychol, 2013; 49: 1833-1847. doi: 10.1037/a0031041.

36. Steptoe A. Control and stress. In: Fink EG ed. Encyclopedia of stress. Vol. 1. Academic Press, New York, 2000: 526-532 .

37. Manson JW. A review of psychoendocrine research on the pituitary-adrenal cortical system. Psychosomatic Med, 1968; 30: 576-607.

38. Seeman TE, Berkman LF, Gulanski R et al. Self-esteem and neuroendocrrne response to challenge: MacArthur Successful Aging Studies. Psychosomatic Research, 1995; 39: 69-84. 